\title{
Quérion causado por Microsporum gypseum em um cão
}

\author{
Kerion caused by Microsporum gypseum in a dog \\ Rafael Rodrigues Ferreira', Mauro Luís da Silva Machado ${ }^{2}$, Andréia Spanamberg ${ }^{3}$ \& Laerte Ferreiro ${ }^{3}$
}

\begin{abstract}
RESUMO
Quérion (dermatofitose nodular) é uma apresentação clínica de micose cutânea caracterizada por uma dermatite profunda que varia de uma reação granulomatosa até piogranulomatosa, com aspecto de nódulo edematoso, circular e alopécico. Em animaisé causado principalmente pelas espécies de dermatófitos Microsporum gypseum, M. canise Trichophyton mentagrophytes. Microsporum gypseum é um fungo geofílico, cosmopolita e sua transmissão ocorre por contato com solos contaminados. É relatado um caso de lesão do tipo quérion causada por M. gypseum em um cão da raça Dachshund, fêmea, 4 anos de idade, atendido no Hospital de Clínicas Veterinárias da Universidade Federal do Rio Grande do Sul, com uma lesão circular na região do focinho medindo $4 \mathrm{~cm}$ de diâmetro. Por se tratar de uma lesão dermatofítica com infecção bacteriana e muito prurido, optou-se pelo tratamento tópico com creme contendo associação medicamentosa de miconazol, gentamicina e betametasona, duas vezes ao dia, por quarenta e cinco dias, havendo regressão completa do quadro, sem recidiva clínica. É apresentada uma extensiva revisão de casos similares observados em outros países. Aparentemente trata-se do primeiro caso de quérion registrado em animais na literatura veterinária brasileira com a respectiva identificação do dermatófito.
\end{abstract}

Descritores: quérion, dermatofitose nodular, Microsporum gypseum, dermatófitos, cão, miconazol.

\section{ABSTRACT}

Kerion (nodular dermatophytosis) is a round and nodular edematous reaction to dermatophyte infection, with a patch of erythematous scaling alopecia, characterized by a granulomatous dermatitis to a deep pyogranulomatous inflammation. In animals it is caused mainly by the species of dermatophytes Microsporum gypseum, M. canis and Trichophyton mentagrophytes. Microsporum gypseum is a cosmopolitan geophilic fungus and its transmission occurs from contaminated soil to man and animals. It is described a kerion by Microsporum gypseum causing a circular lesion on the nostril measuring $4 \mathrm{~cm}$ of diameter in a Dachshund, female, 4-years old dog, consulted at the Hospital de Clínicas Veterinárias, Universidade Federal do Rio Grande do Sul, Porto alegre, Brazil. Due to inflammatory lesion and severe pruritus, a topical treatment with miconazole, gentamicin and betametazone ointment was applied twice a day. In 45 days, the lesion was completely recovered. It is presented an extensive review of similar cases reported in other countries. Aparently, this case appears to be the first report of Kerion in animals in Brazilian publications with the proper identification of the dermatophyte.

Key words: kerion, nodular dermatophytosis, Microsporum gypseum, dermatophytes, dog, miconazole. 


\section{INTRODUÇÃO}

A dermatofitose canina, que se manifesta de forma heterogênea, pode ser diagnosticada a partir de sinais clínicos variados tais como: áreas alopécicas nodulares focais ou disseminadas, com ou sem pápulas foliculares, acompanhadas de variável grau de eritema, descamação e crostas. Por outro lado, podem ocorrer apresentações clínicas do tipo quérion, pseudomicetoma e onicomicose [7,21].

A apresentação do tipo quérion, também denominado dermatofitose nodular, é a manifestação clínica de uma micose cutânea caracterizada por uma dermatite profunda que varia de uma reação granulomatosa até piogranulomatosa, com aspecto de nódulo edematoso, circular e alopécico [5,8,15]. Este quadro é reflexo de uma resposta inflamatória aguda, resultante de uma reação de hipersensibilidade do hospedeiro, estimulada pelos produtos metabólitos do dermatófito [9]. Em muitos casos coexiste uma infecção bacteriana que é normalmente causada por Staphylococcus intermedius [8].

Em animais, os principais dermatófitos descritos como causadores de quérion são as espécies Microsporum canis, M. gypseum e Trichophyton mentagrophytes. O Microsporum gypseum é um fungo geofílico, cosmopolita e sua transmissão ocorre por contato com solos contaminados.

O objetivo do relato é descrever um caso quérion por Microsporum gypseum, quadro clínico que, embora descrito como relativamente comum em cães, efetivamente é muito pouco registrado na literatura.

\section{RELATO DO CASO}

Um cão da raça Dachshund, fêmea, 4 anos de idade, foi atendido no Hospital de Clínicas Veterinárias da Universidade Federal do Rio Grande do Sul com histórico de apresentar há aproximadamente 15 dias uma lesão circular na região do focinho. Não ocorreu envolvimento de outros animais ou pessoas da casa. O animal não apresentava nenhum sinal clínico sistêmico. A única alteração encontrada ao exame foi uma lesão do tipo quérion, lado direito da face, nas imediações do focinho, medindo $4 \mathrm{~cm}$ de diâmetro, com possível infecção bacteriana secundária (Figura 1). Não houve fluorescência ao exame dos pêlos com a Lâmpada de Wood.

Para cultura fúngica foram coletados pêlos adjacentes à lesão, a qual foi previamente desinfectada com álcool $70^{\circ} \mathrm{GL}$. O exame direto foi negativo. O pelame foi semeado em meio de Ágar Sabouraud Dextrose adicionado de cloranfenicol e ciclohexamida e incu- bado a $25^{\circ} \mathrm{C}$. A identificação de Microsporum gypseum foi feita através da identificação através da observação das características macroscópicas das colônias e de macroaleuroconídios típicos das características macroscópicas das colônias e da observação de macroaleuroconídios típicos [20].

\section{DISCUSSÃO}

É muito restrito o número de publicações sobre a ocorrência deste quadro clínico particular de dermatofitose em cães. Encontrou-se somente um registro documentado de quérion na literatura veterinária brasileira, mas sem a informação do agente causal [12].

Especificamente em relação ao quérion causado por Microsporum gypseum foram encontrados alguns registros em cães nos Estados Unidos e na Europa $[1,2,7,8]$. Também existem esparsos registros da participação de $M$. canis $[3,6,10,13]$ e Trichophyton mentagrophytes [14] como desencadeadores deste quadro clínico.

No Brasil, recentemente um estudo (1996-2000) envolvendo milhares de crianças registrou a ocorrência de 9 casos de quérion causado por $M$. canis, $M$. gypseum e Trichophyton tonsurans que é um dermatófito antropofílico [16].

No quadro clínico relatado optou-se pelo tratamento tópico com creme contendo associação medicamentosa de miconazol, gentamicina e betametasona, duas vezes ao dia. A literatura registra divergências sobre a forma de tratamento mais eficaz para as dermatofitoses. Alguns autores indicam a terapia sistêmica como forma ideal para a cura, citando os derivados dos imidazóis, triazóis, antimicrobianos com poder antifúngico (griseofulvina) [4,17], alilaminas (terbinafina) e benzoilfenilurea (lufenuron) [17-19], como opções de tratamento. Já outros autores preconizam o tratamento tópico, salientando que drogas com ação antibacteriana e antifúngica (clorexidina) [21], derivados dos imidazóis [17,19] e até mesmo, associação entre eles, seriam suficientes para a regressão do quadro clínico [21]. Estes mesmos autores enfatizam a importância do emprego da via tópica, por se evitar uma forma mais invasiva de tratamento e o provável aparecimento de efeitos colaterais indesejáveis [11,21].

Trinta dias após a consulta o animal retornou ao Hospital e observou-se que a lesão havia regredido por completo. Foi recomendado, mesmo assim, a continuação do tratamento por mais duas semanas para evitar recidiva clínica [17]. Quarenta e cinco dias após a primeira consulta, novamente não se observou alteração clínica (Figura 2) e, então, a mediação foi suspensa. 


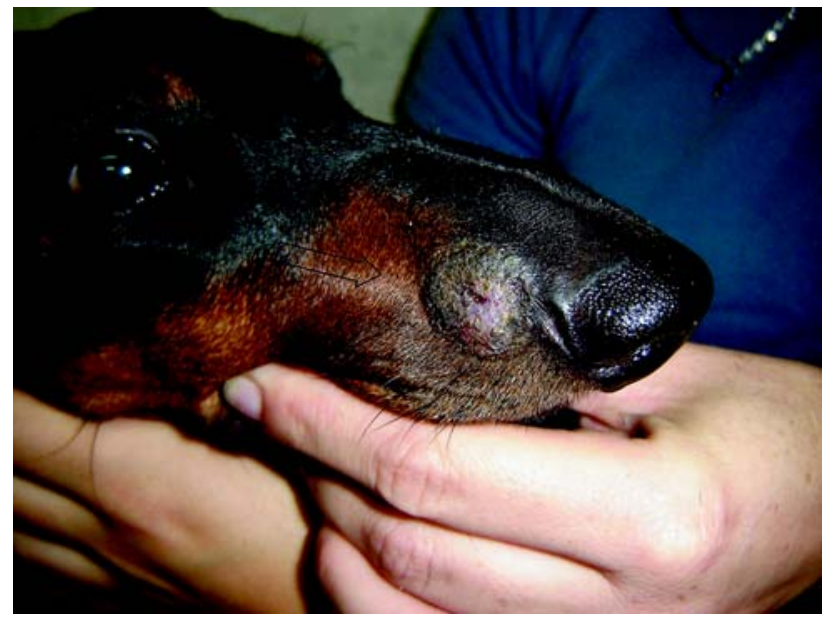

Figura 1. Lesão inflamatória e piogranulomatosa do tipo quérion, localizada no focinho de um cão da raça Dachshund, fêmea, 4 anos de idade.

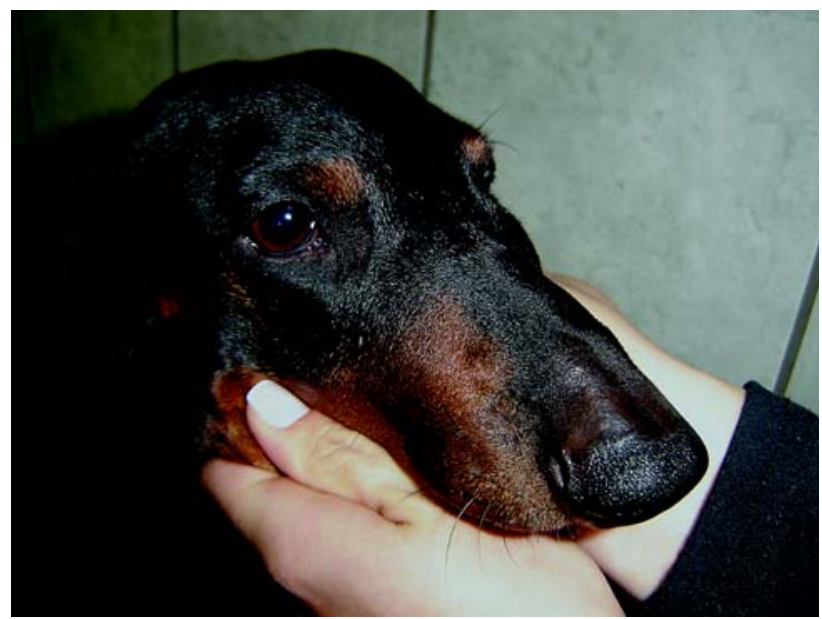

Figura 2. Foto mostrando a regressão total da lesão do tipo quérion no focinho do cão da raça Dachshund, após 45 dias de tratamento tópico com creme contendo associação medicamentosa de miconazol, gentamicina e betametasona.

\section{REFERÊNCIAS}

1 Carlotti D.N. \& Bensignor E. 1999. Dermatophytosis due to Microsporum persicolor (13 cases) or Microsporum gypseum (20 cases) in dogs. Veterinary Dermatology. 10: 17-27.

2 Carlotti D.N. \& Couprie B. 1988. Dermatophyties du chien et du chat: actualités. Pratique Médicale et Chirurgicale de l'Animal de Compagnie. 16: 449-457.

3 Dromigny E. \& Chermette R. 1981. Les teignes dues à Microsporum canis chez les carnivores domestiques et leur transmission à l'homme: Trois cas cliniques. Le Point Vétérinaire. 13 : 53-60.

4 Costa E.O. \& Gorniak S.L. 2002. Agentes antifúngicos e antivirais. In: Spinosa H. S.; Gorniak S. L. \& Bernardi M. M. (Eds). Farmacologia aplicada à Medicina Veterinária. Rio de Janeiro: Guanabara Koogan, pp. 431-442.

5 Cucé L.C. \& Fiesta Neto C. 2001. Manual de Dermatologia. 2. ed. São Paulo: Ateneu, p.182.

6 Ferreiro L. 1995. Étiopathogénie des infections à Microsporum canis. Étude d'une exoprotéase kératinolytique. 193p. Créteil, France. Thèse (Doctorat en Sciences de la Vie et de la Santé) - Faculté de Medecine de Cretéil, Université Paris XII.

7 Foil C.S. 1998. Dermatophytosis. In: Greene C.E. (Ed). Infectious Diseases of the Dog and Cat. Philadelphia: W.B. Saunders Co., pp. 529-542.

8 Koutinas A.F., Saridomichelakis M., Lekkas S. \& Koutinas C.K. 2003. Clinical and histopathological aspects of dermatophyte kerion in the dog: a retrospective study of 20 spontaneous cases.[abstract ]. In: ESVD and ECVD 2002 Abstracts (Nice, France). Veterinary Dermatology. 14: 243.

9 Lehmann P.F. 1985. Immunology of fungal infections in animals. Veterinary Immunology and Immunopathology. 10: 33-69.

10 Logan M.R., Raskin R.E. \& Thompson S. 2006. "Carry-on" dermal baggage: a nodule from a dog. Veterinary Clinical Pathology. 35: 329-331.

11 Lorenz M.D., Cornelius L.M. \& Ferguson D.C. 1996. Terapêutica clínica em pequenos animais. Rio de Janeiro: Inter-livros, $484 \mathrm{p}$.

12 Maciel A.S. \& Viana J.A. 2005. Dermatofitose em cães e gatos: uma revisão - primeira parte. Clínica Veterinária. 56: 48-56.

13 Male O., Thurner J. \& Juksch W. 1980. Dog and cat as sources of Human deramtomycoses. In: Preusser J. (Ed). Medical Mycology, Zentralblat für Bakteriologie. (Supp 8): 353-360.

14 Medleau L. \& Hnilica K.A. 2001. Dermatophytic Granuloma and Pseudomycetoma. In: Small Animal Dermatology - A Color Atlas and Therapeutic Guide. Philadelphia: W.B. Saunders Co., p.45.

15 Midgley G., Clayton Y.M. \& Hay R.J. 1998. Micologia Médica. São Paulo: Manole, p.38.

16 Moraes M.S., Godoy-Martínez P., Alchorne M.M.A., Boatto H.F. \& Fischman O. 2006. Incidence of Tinea capitis in São Paulo, Brazil. Mycopathologia. 162: 91-95.

17 Moriello K.A. 2004. Treatment of dermatophytosis in dogs and cats: review of published studies. Veterinary Dermatology. 15: $99-107$. 
18 Olivares L.R.C., Gayosso P.M., Martinez R.L., Velazques I.A.R. \& Soli E.S.R. 2001. Effectiveness of terbinafine in the eradication of Microsporum canis from laboratory cats. Mycoses. 44: 95-97.

19 Paterson S. 1999. Miconazole/chlorhexidine shampoo as an adjunct to systemic therapy in controlling dermatophytosis in cats. Journal of Small Animal Practice. 40: 163-166.

20 Rebell G. \& Taplin D. 1974. Dermatophytes - Their recognition and Identification. 2nd edn. Coral Gables: University of Miami Press, 124p.

21 Scott D.W., Miller W.H. \& Griffin C.E. 2001. Fungal skin diseases. In: Muller and Kirk's Small Animal Dermatology. 6th edn. Philadelphia: W.B. Saunders Co., pp.336-361. 